\title{
Regional Environmental Quality and Cost Efficiency of International Tourist Hotels in Taiwan
}

\author{
Chin-Tsu Chen ${ }^{1}$, Jin-Li Hu ${ }^{2} \&$ Shin-Lung Lin $^{2}$ \\ ${ }^{1}$ Department of Commercial Design and Management, National Taipei University of Business, Taiwan \\ ${ }^{2}$ Institute of Business and Management, National Chiao Tung University, Taiwan \\ Correspondence: Jin-Li Hu, Institute of Business and Management, National Chiao Tung University, Taiwan. Tel: \\ 886-02-2381-2386 ext. 57641. E-mail: jinlihu@gmail.com
}

Received: August 5, 2014 Accepted: August 18, 2014 Online Published: September 11, 2014

doi:10.5539/eer.v4n3p58 URL: http://dx.doi.org/10.5539/eer.v4n3p58

\begin{abstract}
The purpose of this study is to compute the cost efficiency of international tourist hotels (ITHs) in Taiwan and analyze how regional environmental quality affects cost efficiency. The study collects a variety of operating data of international tourist hotels in Taiwan between 1998 and 2009 from the Annual Tourist Hotels Operational Analysis Report, as published by the Tourism Bureau. The data of regional environmental quality are collected from the Taiwan Environment Data Warehouse. This study first uses data envelopment analysis (DEA) for computing cost efficiency, and then applies the truncated regression to investigate the impact of environmental indicators on cost efficiency. Namely, it is a two-stage DEA-regression method. The empirical results indicate that the density of pungent air pollutants, such as $\mathrm{O}_{3}$ and $\mathrm{SO}_{2}$, have significantly negative impacts on the cost efficiency of ITHs in Taiwan. However, the high volume of waste disposal and low recycling rate reflect a higher business activity intensity in a region, which positively enhances ITHs' cost efficiency.
\end{abstract}

Keywords: international tourist hotels, cost efficiency, environmental quality

\section{Introduction}

In recent years, the rapid economic development and improved quality of material life have led to a relatively busy, fast, and oppressive pace of life. Therefore, the demand for leisure travel has increased dramatically, and the tourism industry has been regarded as one of star industries of the 21 st century. In recent years, due to intense changes in natural environments, the world focuses on issues of environmental protection. Consequently, environmental issues have a far-reaching impact on the tourism industry. In addition to the economic development and employment opportunities brought by the tourism industry, countries in the world pay greater attention to the use of natural and human resources to develop and maintain natural ecological environments that facilitate sustainable development.

According to the statistical data of the Tourism Bureau, the Ministry of Transportation, 9.415 million tourists went sightseeing in Taiwan in 2010, growing from 8.142 million in 2009 (15.6\%). Moreover, in the most recent 10 years, tourists to Taiwan and Taiwanese tourists going overseas have been increasing. The percentage of tourists for sightseeing purposes, against the total number of tourists, grew from $36 \%$ in 2001 to $58 \%$ in 2010 ; with mainland China the largest source of tourists, followed by Japan, Southeastern Asian countries, Hong Kong, Macao, and the United States. According to the data of World Tourism Organization (2011), the total number of tourists in the world in 2010 was 935 billion, an increase of 7\% compared to that in 2009. The Asia-Pacific region is the first area of economic recovery, and attracted a total of 204 million international tourists in 2010, growing by about $13 \%$, as compared to 181 billion people in 2009 , as the second only to the Middle East. In addition, according to the statistical data of World Travel \& Tourism Council (WTTC), in 2010, the global tourism industry (including tourism-related industries, input, and taxation ) accounted for about $9 \%$ of the GDP (equivalent to 5.7 trillion USD), growing by about $1.7 \%$, as compared to that in 2000 . In 2010 , the tourism industry gradually recovered.

Taiwan is surrounded by the sea and located in a maritime transport hub in East Asia. In history, Taiwan is a central location fought over by western and eastern powers and has become a rare cultural melting pot. In terms of geographic resources, as Taiwan is located in the Pacific seismic belt, geological activities are rich, which 
render Taiwan a rich geographic environment with great sightseeing values. Therefore, tourism has become one of the most promoted industries of the government, which launched various policies to attract international tourists; for example: in 2011, the Tourism Bureau shot Taiwan's first global sightseeing movie, marketing Taiwan to the world, signed free-visa agreements with 42 countries, and opened to mainland China tourists for sightseeing tours in Taiwan. Counties and cities in Taiwan host various festivals with local characteristics to attract tourists. According to the 2010 survey by the Taiwan Tourism Bureau on the consumption and movements of tourists to Taiwan, from 2001 to 2010, tourists to Taiwan increased from 2,831,035 to 5,567,277, growing by about $87 \%$; and tourism foreign exchange earnings rose from 4,335 billion USD to 8,719 million USD, growing by about $101 \%$.

The tourism industry will become an important industry with a direct impact on Taiwan's development, and the government has increased emphasis on tourism industry development. Studies on the tourism industry will contribute to industrial development and provide the Government with directions and reference for policy-making. According to the ITH summary of operations in 2010, as published by the Tourism Bureau, Ministry of Transportation, accommodation for tourists to Taiwan is mainly in hotels, including ITHs, general hotels, and tourist hotels. Therefore, when attracting more international tourists to Taiwan, the hotel industry is an important link for the development of the industry. Taiwan's ITHs rose from 44 hotels in 1985 to 70 hotels in 2010. With the increasingly fierce competition in the hotel industry, only those that can control costs and properly use resources can achieve the highest efficiency to survive in the tourism industry.

According to the 2010 survey and statistics on the tourism of Taiwanese people, conducted by the Tourism Bureau, Ministry of Transportation, regarding tourism activities, people are mainly engaged in "natural sightseeing activities", "cultural experience", "sports activities", "amusement park activities", "gourmet activities", and "leisure activities". "Natural sightseeing activities" accounts for $53.8 \%$ as the highest. It thus can be concluded that Taiwan's natural environment has a considerable impact on the tourism industry. The selection of hotels is an important activity in sightseeing. The natural environment quality of ITHs, such as air quality, waste recycling, and processing procedures, can be major factors affecting tourists when determining the location of accommodations. Therefore, the purpose of this study is to investigate the linkage between natural environmental indicators and the international tourist hotel's cost efficiency.

\section{Literature Review}

\subsection{Environment Indicators}

Many scholars have studied the relationship between the tourism industry and the environment. Studies have pointed out that the success of tourism and hotel industries depends largely on providing a clean natural environment. According to the survey, the European hotel industry and Scandinavian hotel guests believe that environment is the major key factor to the development and success of the tourism industry (Bohdanowicz 2003). According to the needs of tourists, the environmental quality of natural attractions is an important part of tourism quality. Therefore, to maintain a high quality overall tourism environment is very important to the competitiveness of most tourist destinations (Mihalic 2000).

Huybers and Bennett (2003) pointed out that, as the tourism industry depends on natural environment quality, tourism operators will have motivations for voluntary environmental protection activities. Some studies have suggested that environment is very important to the competitiveness of the tourism industry in tropical Northern Queensland, and undamaged environments have a significant impact on the needs of tourists. By questionnaire survey, $\mathrm{Li}$ (2004) pointed out that there are five types of tourist attractions: plants, animals, ecosystems and landscapes, history and religion, fresh air and water. The most attractive type is fresh air and water; $68.3 \%$ of tourists to the Nature Reserve of Tianmu Mountain in Zhejiang come because of the quality of air and water. The second mostly preferred is the ecosystems and landscapes type; $59.2 \%$ of tourists enjoy ecosystems and beautiful sceneries. The third most popular type is plants, with $59 \%$ of tourists claiming they are attracted by the primitive plants in the Nature Reserve of Tianmu Mountain in Zhejiang. In 2006, the significance of high environmental quality to tourism industry development was recognized by the World Trade Organization (WTO) (Bohdanowicz 2006). However, Kirk (1995) pointed out that the hotel industry also produces some undesirable emissions, such as carbon dioxide, CFCs, noise, smog, and odors, as well as wasted resources, such as energy, water, food, and packaging, which may result in natural appeal losses for beautiful scenery, natural hydrological structures, clean water, fresh air, and species diversity, due to pollution. Therefore, as the tourism industry depends on natural environment quality, it has a special position in the sustainable development of environments. Although the tourism industry may lead to environmental damage, it can positively contribute to natural environments; for example, advocacy of the value of natural environments to people, the creation of incentive mechanisms for 
improving environments, improvement of environmental protection awareness, and encouragement of tourists to exercise environmental protection actions (Blanke and Chiesa 2007).

In recent years, due to rising environmental protection awareness, many industries are faced with pressure to enhance environmental protection awareness, and the hotel industry is no exception. The hotel industry can contribute to the improvement of environmental quality by reducing its impact on the environment. However, for operators of the hotel industry, most are profit-making units, and whether implementations of environmental protection activities can produce sufficient benefits is a key issue. Although benefits from implementing environmental protection activities may not be sufficient, the hotel industry is actually faced with pressures from both consumers and law enforcement (Knowles et al. 1999).

Grove et al. (1996) pointed out that organization may protect the environment through recycling of packaging, recycling materials, and reducing data. For tourism and hotel industries, it is not difficult to make commitments for environmental protection, as recycling waste water is a means of environmental protection.

Fairweather et al. (2005) also pointed out that the most commonly seen types of information expected by tourists from environmental protection labels are detailed certified information, recycling information, and information regarding measures taken to protect the environment. Previous studies have also pointed out that the tourism industry should be concerned about the repeated use of resources in environmental management, rather than the reduced use of resources (Hunter and Green 1995).

Font and Tribe (2001) studied a variety of different awards and labels on environmental management. In some cases, only one standard, such as the presence or absence of chlorine, is evaluated; while in other cases, multiple indicators are evaluated. However, the greatest disadvantage of these awards is that they cannot be universally applied, that is, they are not applicable to all industries or hotels in all countries, as environmental problems vary in different countries' hotel and industrial environments.

\subsection{Hotel Efficiency}

Most previous studies on hotel operating efficiency conducted analysis using the inefficient frontier method. Wassenaar and Stafford (1991) proposed using hotel room usage as the measurement indicator (Wassenaar and Stafford 1991). However, due to the development of DEA and SFA in recent years, and the wide use of these two methods, more and more studies adopt DEA and SFA to measure hotel industry operating efficiency, in particular, DEA is the most widely applied. With many characteristics, DEA can convert multiple inputs into outputs to analyze efficiency; therefore, DEA is preferred in many studies (Charnes 1994). For example, Anderson, Fok, and Scott (2000) used DEA to compute the overall efficiency, technology efficiency, pure technology efficiency, and scale efficiency of 48 hotels in the United States by using five input items, including number of full-time staff, number of rooms, game-related total cost, total cost of food and beverage, and other cost, and the total revenue as the output items, and found that the overall average efficiency is about $42 \%$, while the major cause of relatively low efficiency is low allocative efficiency.

By using the number of full-time employees, labor costs, number of rooms, the hotel area (square meters), the book value of assets, operating expenses, the external cost of input items and turnover, number of tourists, and accommodation revenue as output items, Barros (2005) used the CCR model of DEA to explore the efficiency of 43 hotels in the Pousadas de Portugal chain group of Portugal in 2001. According to the findings of the study, most hotels have production efficiency, and technical efficiency is $90.9 \%$ in the case of constant returns to scale; in variable returns to scale, technical efficiency is $94.5 \%$. The efficiency of hotels in the city or near city is higher than that of hotels in rural areas. By using the number of full-time employees, the book value of the assets, number of rooms, the price of labor, the price of capital, and room price as input items, and turnover, number of tourists, and accommodation revenue as output items, Barros and Mascarenhas (2005) used cost DEA to explore the economic efficiency of 43 hotels of the Pousadas de Portugal chain group of Portugal in 2001. According to the research findings, the type of hotel has no impact on economic efficiency. Hotels with more rooms have a higher level of efficiency, and hotels farther from tourism routes have lower efficiency.

In recent years, a number of Taiwanese scholars used DEA to study hotel operating efficiency. By using total operating expenses, number of employees, number of rooms, total floor area of food and beverage sectors, number of employees of the accommodation sector, the number of food and beverage sector staff, and catering cost as the input items, and total operating revenue, number of rooms, average room occupancy revenue, the average salary of the food and beverage sector staff, the accommodation sector's total revenue, and food and beverage sector's total operating revenue as output items, Tsaur (2001) used DEA to study the efficiency of 53 ITHs from 1996 to 1998 in Taiwan. According to the research findings, the average operating efficiency is $87.33 \%$, thus, the operation of Taiwan's tourist hotels is efficient. By using the number of full-time employees, 
the total area of rooms, food and beverage sector's total floor area, and operating expenses as input items, and room revenue, food revenue, and other revenue as output items, Hwang and Chang (2003) used DEA to measure the operating efficiency of 45 hotels in Taiwan in 1998, and applied Malmquist production variables in order to investigate the change in efficiency during the period between 1994-1998. The research findings suggest that the average efficiency in 1998 was $79.16 \%$.

$\mathrm{Hu}$ et al. (2009) also used DEA in analysis of cost efficiency, allocative efficiency, and overall technology efficiency, of ITHs (International Tourist Hotels) in Taiwan during the period of 1997-2006, by using the number of rooms, number of employees, and catering floor area as input items, and the average operating cost of a room, the average annual salary of the employees, and food and beverage average operating cost as the input cost, and food and beverage total revenue, accommodation revenue, and other revenue as the output items. According to the research results, the cost efficiency of these hotels is $57 \%$ low efficiency. Chain systems, non-urban locations, and occupancy rates have significant impact. In addition to DEA, Hu et al. (2010) used SFA to discuss cost efficiency and causes of inefficiency of 66 hotels in Taiwan during the period of 1997-2006, using average labor costs, the average of other operating expenses, and the average cost of catering floor area as input items, and room revenue, catering revenue, and other operating revenue as the output items. According to the findings of this study, the average cost efficiency of ITHs in Taiwan is $91.15 \%$. Chain systems, number of tour guides, and international transportation can significantly improve the cost efficiency of Taiwan's ITHs.

By using the number of rooms, number of employees, and catering total floor area as input items, the average operating cost of a room, the average annual salary of the employees, food, and average operating cost, as input costs, and catering total revenue, room revenue, and other revenue, as the output costs, Chen et al. (2010) used DEA to explore the cost efficiency of ITHs in Taiwan during the period of 1997-2007, and explored the impact of nationality of tourists on cost efficiency. According to the research findings, between 2002 and 2005, the average cost efficiency of ITHs in Taiwan tended to gradually decline. In terms of tourist nationality, tourists from Taiwan, North America, Japan, and Australia have a positive impact on the cost efficiency of hotels, while overseas Chinese and European tourists have a negative impact on cost efficiency.

\section{Research Method}

This study applied the two-stage analysis method to analyze the impact of environmental indicators of tourist hotels in Taiwan on operating cost efficiency. In the first stage, the data envelopment analysis (DEA) is applied in the analysis of the operating efficiency of tourist hotels. In the second stage, using the operating efficiency values of hotels obtained in the first stage as the dependent variables, and environmental indicators as the independent variables, this study applied the regression method to analyze the impact of environmental indicators on operating efficiency.

\section{$D E A$}

The concept of DEA was first proposed by Farrell (1957), who introduced the concept of production frontier into the measurement of relative efficiency. The decision making units of the production frontier are regarded as relatively efficient, while decision making units inside the production frontier are regarded as relatively inefficient. Charnes et al. (1978), based on the Farrell theory, used the linear programming method to add situations with multiple inputs and outputs to measure production efficiency in 1978. This was the first DEA model, known as the CCR model. However, the CCR model is under the assumption of constant returns to scale (CRS). Later, Banker et al. (1984) relaxed CRS assumption into variable returns to scale (VRS) by incorporating the convexity constraint into a DEA model.

At present, DEA models can be divided into the input-oriented model that measures input relative efficiency and the output-oriented model that measures output. This study used the input-oriented VRS-DEA model, which assumes that each hotel has $\mathrm{K}$ input items and $\mathrm{M}$ output items, using $\mathrm{q}_{\mathrm{i}}$ to represent the output vector of the ith decision making unit $(\mathrm{M} \times 1) ; \mathrm{x}_{\mathrm{i}}$ to represent the input vector of the ith decision making unit $(\mathrm{K} \times 1) ; \lambda$ to represent the weight vector of each decision making unit $(\mathrm{N} \times 1) ; \mathrm{w}_{\mathrm{i}}$ to represent the price vector of various input items of the ith decision making unit; and $\mathrm{x}_{\mathrm{i}}{ }^{*}$ to represent the vector of various input items under the minimized input cost of No. i decision making unit, the model is as below:

$$
\begin{array}{ll} 
& \text { Min } \mathrm{w}_{\mathrm{i}}^{\prime} \mathrm{x}_{\mathrm{i}}^{*} \\
& \mathrm{x}^{*}, \lambda \\
\text { s.t. } & -\mathrm{q}_{\mathrm{i}}+\mathrm{Q} \lambda \geq 0 \\
& \mathrm{x}_{\mathrm{i}}{ }^{*}-\mathrm{X} \lambda \geq 0
\end{array}
$$




$$
\begin{aligned}
& \sum \lambda=1 \\
& \lambda \geq 0
\end{aligned}
$$

\subsection{Truncated Regression}

This study adopted the two-stage analysis method. In the second stage, truncated regression is applied. Most previous studies using the two-stage method used the Tobit regression model, as proposed by Tobin (1958). However, DEA estimates the relative efficiency value of the decision making unit according to the characteristics of non-parameters. Tobit regression assumes that efficiency errors are of normal distribution, which will result in the relative bias of Tobit regression results. Simar and Wilson confirmed that, when the efficiency value is an explained variable, truncated regression can produce estimated results closer to the actual parameter values, as compared with the Tobit regression method (Simar and Wilson 2007).

\subsection{Date Sources}

This study collects various operation-related data of ITHs in Taiwan from 1998 to 2009, taken from the Annual Tourist Hotels Operational Analysis Report, published by the Tourism Bureau, and selected appropriate revenues and input items as the variables for the calculation of efficiency value. In addition, to avoid the problem of different potential measurement benchmarks, as caused by the different monetary supplies of various years, all nominal variables in this study were converted into actual variables by GDP deflator, with 1998 as the benchmark year to avoid distortion by the price level changes. Moreover, the number of official ITHs may be different, due to bankruptcy or ITH standards formulated by the Tourism Bureau, thus, to collect as much data as possible, this study used unbalanced vertical and horizontal data to estimate the relative efficiency of ITHs. The number of observations from 2001 to 2009 is as shown below: 1998 (53 hotels), 1999-2001 (55 hotels), 2002 (56 hotels), 2003-2004 (58 hotels), 2005-2006 (57 hotels), 2007 (58 hotels), 2008 (59 hotels), and 2009 (56 hotels).

The hotel industry's output is mainly measured by revenue. The major sources of revenue for ITHs in Taiwan can be roughly divided into three types of accommodation and beverage revenues, which account for more than $80 \%$ of the total. Other revenues, including the revenue of swimming pool, laundry revenue, and rent and services revenues, account for less than $20 \%$. In terms of input, the hotel's input roughly consists of employees, equipment, and capital. The employee salaries represent the human resources invested by a hotel, and the total number of rooms and the catering floor areas can represent the capital input of the hotel (Hwang and Chang 2003). With reference to previous literature, the inputs are divided into the number of rooms, number of employees, and catering floor area, which is multiplied by the average operating cost of a room, the average annual salary of the employees, and food and average operating cost, respectively. Hotel operational revenue, inputs and input costs used by (Hu et al. 2009) are as shown below:

1. Output variables

(1) Food and beverage total revenue

(2) Accommodation revenue

(3) Other revenue

2. Input variables

(1) The number of rooms

(2) Number of employees

(3) Catering floor area

3. Input cost

(1) The average operating cost of a room, meaning the total expenses of a room, as the division of total revenue by the number of rooms;

(2) The average annual salary of the employees;

(3) Food and average operating costs; the division of the relevant expenses of the catering sector by the catering floor area.

Environmental indicators are used as the environmental variables affecting hotel operating efficiency. Regarding environmental indicators, the Council of Sustainable Development, the Executive Yuan, held four rounds of "Ministerial Coordination Conference on Sustainable Development Indicators" since February 2009, inviting representatives from relevant ministries and the private sector to determine the sustainability and accessibility of new indictors. In the No. 29 working meeting of the Council of Sustainable Development, held on December $31^{\text {st }}$, 
2009, the second version of sustainable development indicators of Taiwan, covering 12 themes, 41 subthemes, and 94 indicators (number of indicators increased by 52 as compared to the original version), was approved. The indicators in the environmental perspective can be roughly categorized into four major types, including air and water quality, and waste and environmental management.

Regarding the dependence of the tourism industry on environmental quality, as tourists prefer natural environments, and are concerned with air quality, they account for the greatest percentage. Moreover, it has been mentioned in previous studies that the hotel industry should consider recycling resources, rather than a reduction in the use of resources, for environmental management (Hunter and Green 1995). The purpose of this study is to explore the impact of environmental quality on hotel operating efficiency. Therefore, regarding environmental indicators, the air and waste categories of indicators in the environmental dimension of the sustainable development indicator system, as developed by the Executive Yuan, were used as measurement indicators. The data of various monitoring stations were obtained from Taiwan Environment Data Warehouse (2012), which is maintained by the Environmental Protection Administration in Taiwan. The variables used in this study are as shown below:

1. Air

(1) $\mathrm{SO} 2$ density

(2) $\mathrm{NO} 2$ density

(3) CO density

(4) $\mathrm{O} 3$ maximum $8 \mathrm{hr}$ average density

2. Waste

(1) Waste recycling rate

(2) Average daily waste generated per person

In order to avoid the impact of excessive environmental indicators on hotel operating efficiency, which can cause bias, this study adds the variables that commonly affect operating efficiency as the control variables to avoid an overreaction of environmental variables. The control variables used in this study are as shown below:

1. Chain System (Chain $=1$ and non-chain $=0)$

2. Rural level (Rural county $=2$, Metropolitan County $=1$, and Metropolitan City $=0$ )

\section{Results}

The statistical results of the business operations of Taiwan's ITHs are elaborated upon, as shown in Table 1. The revenue of Taiwan's ITHs mainly comes from catering and accommodation of tourists. The average catering revenue is about 2.74 million NTD, which is slightly more than the accommodation revenue of 2.38 million NTD, possibly because hotel restaurants have become one of the major choices of social gathering for an increasing number of people dining out. Besides accommodation, catering has become the focus of operation for tourist hotels in Taiwan. However, for different business operational patterns, chain or non-chain business models can result in great differences in scale; thus, the standard deviation is considerably large.

\subsection{Hotel Efficiency Analysis}

In this study, hotel operating efficiency is measured by input-oriented cost DEA. By using the DEAP 2.1 software, as proposed by Professor Coelli (1996), the cost efficiency of various hotels is computed during the period of 1998-2009. The average cost efficiency of ITHs in Taiwan are 0.719 (2001), 0.711 (2002), 0.702 (2003), 0.662 (2004), 0.658 (2005), 0.665 (2006), 0.649 (2007), 0.666 (2008), and 0.667 (2009). The results showed that the average cost efficiency of ITHs in Taiwan during the period of 1998-2009 was about $67.8 \%$; in other words, the average input cost of the hotel can be further reduced by $32.2 \%$, while maintaining the state of outputs. 
Table 1. Average values and standard deviations of input, output, and input prices

\begin{tabular}{lrr}
\hline Variable & Mean & S.D. \\
\hline Outputs & & \\
Catering revenue (NTD in 1998 prices) & 275,345 & 274,072 \\
Accommodation revenue (NTD in 1998 prices) & 238,404 & 217,399 \\
Other revenue (NTD in 1998 prices) & 98,269 & 141,214 \\
Inputs & 72,996 & 43,638 \\
$\quad$ Actual number of occupied rooms (room) & 335 & 229 \\
$\quad$ Number of employees (person) & 1,191 & 1,364 \\
$\quad$ Catering total floor area (Ping; 1 Ping = 3.305785 square meters) & 3,060 & 1,336 \\
Input Prices & 526,014 & 156,231 \\
$\quad$ Average room rate (NTD in 1998 prices) & 106,027 & 98,404 \\
Average salary per employee (NTD in 1998 prices) & & \\
Catering cost per Ping (NTD in 1998 prices)
\end{tabular}

The trends of cost efficiency during the period of 1999 2007 were roughly downward, as can be seen in the figure. Namely, during these night years, the cost efficiency of Taiwan ITHs continuously declined, and began improving in 2007. The possible cause of such a phenomenon is the unforgettable major earthquake, 921, in 1999. Many hotels in mountainous regions were seriously damaged. This earthquake scared the Taiwanese, depriving them of their interest in tourism, seriously damaging the tourism industry. By 2008, international hotels' operating efficiency improved a little bit. It is believed that the hotel industry actively improved operating performance as the industry awoke from the financial crisis in 2008. Meanwhile, the government approved opening mainland Chinese tourists for sightseeing in Taiwan, thus, facilitating a steady stream of tourists into the tourism industry of Taiwan, which might improve cost operating efficiency of ITHs in Taiwan.

\subsection{Truncated Regression Analysis}

Following the recommendation of Simar and Wilson (2007), this study used the truncated regression model to replace the traditional Tobit regression, in order to test the impact of environmental indicators on operating efficiency in the second stage. Six environmental indicators are used as the environmental variables, including $\mathrm{SO}_{2}$ density (SO2), $\mathrm{NO}_{2}$ density ( $\left.\mathrm{NO} 2\right), \mathrm{CO}$ density $(\mathrm{CO}), \mathrm{O}_{3}$ maximum $8 \mathrm{hr}$ average density $(\mathrm{O} 38 \mathrm{HR})$, recycling rate (RE), and average daily waste generated per person (GB), while hotel cost efficiency (CE) is used as the dependent variable, coupled with two control variables, including Rural Level (RURAL) and Chain System (CHAIN).

The truncated regression results on cost efficiency are as shown in Table 2. The average daily waste generated per person, $\mathrm{O}_{3}$ maximum $8 \mathrm{hr}$ average density, recycling rate, and $\mathrm{SO}_{2}$ density of the six environmental indicators have significant impact on operating efficiency. The average daily waste generated per person has a positive impact on operating efficiency. It can be concluded that higher levels of economic activities can contribute more to the hotel operating efficiency. Indicators of $\mathrm{O}_{3}$ maximum $8 \mathrm{hr}$ average density, recycling rate, and $\mathrm{SO}_{2}$ density have negative impact on operating efficiency. $\mathrm{As}_{3}$ and $\mathrm{SO}_{2}$ are gases with pungent odors and a toxicity level of $\mathrm{O}_{3}$, it can lead to headaches, eye burning, and irritation of the respiratory tract, which have a bad influence on tourist accommodation and catering. Therefore, the hotel industry should select locations away from industrial areas prone to $\mathrm{SO}_{2}$ and $\mathrm{O}_{3}$. Waste recycling can increase the cost of doing business; therefore, it has a negative impact on cost efficiency.

This paper finds that as the rural level increases, the cost efficiency of an ITH decreases, implying that the degree of urbanization in the local area helps improve the cost efficiency of an ITH, which is consistent with the findings of $\mathrm{Hu}$ et al. (2010). The chain store system significantly helps improve the cost efficiency of ITHs, which is consistent with findings of Hu et al. (2009, 2010). 
Table 2. Truncated regression results of environmental variables on cost efficiency

\begin{tabular}{lcc}
\hline \multicolumn{1}{c}{ Variables } & Estimation coefficient & P-value \\
\hline Rural level (Rural) & -0.07097 & $<0.0001^{* * *}$ \\
CO density (CO) & -0.06578 & 0.5165 \\
Average daily waste generated per person & & \\
$\quad$ (GB) & 0.15715 & $0.0032^{* * *}$ \\
Chain system (CHAIN) & 0.09411 & $<0.0001^{* * *}$ \\
NO2 density (NO2) & -0.00011 & 0.9659 \\
O3 maximum 8hr average density (O38HR) & -0.00233 & $0.0145^{* *}$ \\
Recycling rate (RE) & -0.00145 & $0.0446^{*}$ \\
SO2 density (SO2) & -0.02362 & $<0.0001^{* * *}$ \\
\hline
\end{tabular}

Note: $\quad * * *$ indicates significance at $0.01 ; * *$ indicates significance at 0.05 ; and $*$ indicates significance at 0.10 .

\section{Conclusions}

Taiwan's tourism industry has been rapidly developing in recent years due to the vigorous promotion of the government, and the opening of the tourism market to tourists from mainland China, which brings huge business opportunities to Taiwan's tourism industry. According to the statistics of the Tourism Bureau, about $80 \%$ of Taiwanese travelers choose Taiwan as the tourism destination, the average travel time is approximately 1.49 days, and the average annual number of trips is up to about 6 times. It can thus be concluded that Taiwanese people's demand for tours in Taiwan is considerable. In a tour, the choice of accommodation is very important. The catering revenue of Taiwan's ITHs has also begun to surpass the accommodation revenue; therefore, the hotel industry accounts for considerable volume in the overall tourism industry.

The average cost efficiency of ITHs in Taiwan is about 67.8\% during 1998-2009. Taiwan's hotel industry has made progress, as compared with hotel cost efficiency at $57 \%$ in the period of 1997 2006, as suggested in a study by Hu et al. (2009); however, there still remains space for improvement of cost efficiency. According to the five least efficient hotels, technology efficiency is the major cause for low cost efficiency of hotels with poor performance. Low technology efficiency means some input resources have no corresponding outputs, in other words, there are unnecessary resource inputs. It is recommended that these hotels should re-examine all input resources and observe their industry peers to identify areas of management and resource wastes or seek business consultants to determine which parts of the operating costs can be improved.

This study also finds that the air quality and waste disposal of tourist areas have a definite impact on the operation of local hotels. According to statistical results, tourists are more sensitive to pungent odors in the air, and pungent gases, such as $\mathrm{SO}_{2}$ or $\mathrm{O}_{3}$ in the air, can be easily perceived by tourists. Thus, when hotels must spend extra cost to eliminate odors, local hotels' cost efficiency will become lower.

In addition to causing human discomfort, $\mathrm{SO}_{2}$ will form strong corrosive acids, such as sulfuric and sulfuric acid, when dissolved in water, which may rust metal, fragment plastic, corrupt leather, damage cement walls, thus, shortening the service life of the above items. The above may also be a cause for lower cost efficiency of hotels. The main sources of $\mathrm{SO}_{2}$ include factories and diesel engine vehicles, including railway diesel-electric locomotives, road buses, city buses, and freight trucks. In the future, operators in the hotel industry should be as far removed as possible from areas that may produce high density of $\mathrm{SO}_{2}$, and should avoid the use of diesel vehicles or use high grade diesel oil, with $0.5 \%$ sulfur content, instead of using the ordinary diesel fuel with $1.2 \%$ of ordinary diesel fuel.

Besides pungent odor, $\mathrm{O}_{3}$ can cause unhealthy conditions if inhaled. These features can be easily perceived and consequently lead to negative emotions. $\mathrm{O}_{3}$ is formed by NOx and VOCs after a series of photochemical reactions. The sources of NOx and VOCs include industrial emissions, vehicle emissions, and other sources. Areas of high density $\mathrm{O}_{3}$ include the industrial areas, metropolitan area, traffic arteries, and peri-urban areas. Therefore, hotels should be built far away from areas of high density of $\mathrm{O}_{3}$. It is recommended that operators in the hotel industry should refer to the air quality data published by the air quality observation stations of the Environmental Protection Administration as a factor of consideration.

Moreover, this study found that the average waste generated per person in an area is positively correlated to the hotel's operating efficiency. The two possible factors for relatively high average daily waste generated per person of an area may include: first, the economic activities of the residents in this area are booming, and the volume of waste generated per person will be relatively more. This suggests the area is high in consuming power and 
suitable for hotel business. Second, the large number of tourists generates huge volumes of waste and the local residents produce relatively less waste. It results in the inevitable bias in governmental statistics. However, this also suggests that the tourism resources of this area are favored by tourists in large numbers, thus, this area is suitable for development of the tourism industry. No matter the reason, higher levels of the average daily waste generated per person suggest the area is suitable for businesses of the hotel industry. Therefore, operators of the hotel industry are expected to refer to the waste processing data provided by the Environmental Protection Administration as a criterion to determine the appropriate location for a hotel.

This study also finds that the waste recycling rate of the area surrounding a hotel location has a negative impact on hotel cost efficiency. Resource recycling is a long term trend of social development; however, it is actually a cost to the operators of the hotel industry. Therefore, in the implementation of a resource recycling policy, the government should pay special attention to the impact on tourist hotels and shorten the magnitude of the impact, as possible. In the future, resource recycling items and methods should be taken as research subjects to identify which resource recycling items or methods will cause greater burden on the operators of tourist hotels, which would assist the government and operators of tourist hotels to determine the possible optimal resource recycling programs.

\section{Acknowledgements}

The second author thanks Taiwan's Minitsry of Science and Technology for financial support (NSC101-2410-H-009-044).

\section{References}

Anderson, R. I., Fok, R., \& Scott, J. (2000). Hotel industry efficiency: an advanced linear programming examination. American Business Review, 18(1), 40-48.

Banker, R. D., Charnes, R. F., Cooper, W. W. (1984). Some models for estimating technical and scale inefficiencies in data envelopment analysis. Management Science, 30(9), 1078-1092.

Barros, C. P. (2005). Measuring efficiency in the hotel sector. Annals of Tourism Research, 32(2), 456-477. http://dx.doi.org/ 10.1016/j.annals.2004.07.011

Barros, C. P., \& Mascarenhas, M. J. (2005). Technical and allocative efficiency in a chain of small hotels. International Journal of Hospitality Management, 24(3), 415-436. http://dx.doi.org/ 10.1016/j.ijhm.2004.08.007

Blanke, J., \& Chiesa, T. (2007). The travel and tourism competitiveness report 2007: Furthering the process of economic development. Geneva, Switzerland: World Economic Forum.

Bohdanowicz, P. (2003). A study of environmental impacts, environmental awareness and pro-ecological initiatives in the hotel industry. Licentiate Thesis. Department of Energy Technology, Royal Institute of Technology, Stockholm, Sweden.

Bohdanowicz, P. (2006). Environmental awareness and initiatives in the Swedish and Polish hotel industries survey results. International Journal of Hospitality Management, 25(4), 662-682. http://dx.doi.org/ 10.1016/j.ijhm.2005.06.006

Charnes, A. (1994). Data Envelopment Analysis: Theory, Methodology, and Application. United States: Springer.

Charnes, A., Cooper, W. W., \& Rhodes, E. (1978). Measuring the efficiency of decision making units. European Journal of Operational Research, 2(6), 429-444.

Chen, C. T., Hu, J. L, \& Liao, J. J. (2010). Tourists' nationalities and the cost efficiency of international tourist hotels in Taiwan. Africa Journal of Business Management, 4(16), 3440-3446.

Coelli, T. J. (1996). A guide to DEAP version 2.1: A data envelopemnt analysis (computer) program. CEPA Working Papers, No. 8/96, Armidale: University of New England.

Fairweather, J. R, Maslin, C., \& Simmons, D. G. (2005). Environmental values and response to ecolabels among international visitors to New Zealand. Journal of Sustainable Tourism, 13(1), 82-98. http://dx.doi.org/ $10.1080 / 17501220508668474$

Farrell, M. J. (1957). The measurement of productive efficiency. Journal of the Royal Statistical Society, Series A, $120(3), 253-290$.

Font, X., \& Tribe, J. (2001). Promoting green tourism: the future of environmental awards. International Journal of Tourism Research, 3(1), 9-21. http://dx.doi.org/10.1002/1522-1970(200101/02) 


\section{3:1<9::AID-JTR244>3.0.CO;2-Q}

Grove, S. J., Fisk, R. P., Pickett, G. M., \& Kangun, N. (1996). Going green in the service sector: Social responsibility issues, implications and implementation. European Journal of Marketing, 30(5), 56-66.

Hu, J. L., Chiu, C. N., Shieh, H. S., \& Huang, C. H. (2010). A stochastic cost efficiency analysis of international tourist hotels in Taiwan. International Journal of Hospitality Management, 29(1), 99-107. http://dx.doi.org/ 10.1016/j.ijhm.2009.06.005

Hu, J. L., Shieh, H. S., Huang, C. H., \& Chiu, C. N. (2009). Cost efficiency of international tourist hotels in Taiwan: A data envelopment analysis application. Asia Pacific Journal of Tourism Research, 14(4), 371-384. http://dx.doi.org/ 10.1080/10941660903310060

Hunter, C., \& Green, H. (1995). Tourism and the Environment: A Austainable Relationship? London: Routledge.

Huybers, T., \& Bennett, J. (2003). Environmental management and the competitiveness of nature-based tourism destinations. Environmental and Resource Economics, 24(3), 213-233. http://dx.doi.org/ 10.1023/A:1022942001100

Hwang, S. N., \& Chang, T. Y. (2003). Using data envelopment analysis to measure hotel managerial efficiency change in Taiwan. Tourism Management, 24(4), 357-369. http://dx.doi.org/ 10.1016/S0261-5177(02)00112-7

Kirk, D. (1995). Environmental management in hotels. International Journal of Contemporary Hospitality Management, 7(6), 3-8.

Knowles, T., Macmillan, S., Palmer, J., Grabowski, P., \& Hashimoto, A. (1999). The development of environmental initiatives in tourism: responses from the London hotel sector. International Journal of Tourism Research, 1(4), 255-265.

\section{Copyrights}

Copyright for this article is retained by the author(s), with first publication rights granted to the journal.

This is an open-access article distributed under the terms and conditions of the Creative Commons Attribution license (http://creativecommons.org/licenses/by/3.0/). 